MESTRADO EM CIÊNCIAS DA EDUCAÇÃO

IDARAÍ SANTOS DE SANTANA

IDALICE DEIRÓ NORONHA

A TRAJETÓRIA DA EDUCAÇÃo DE JOVENS E ADULTOS E A EDUCAÇÃo INCLUSIVA NA CIDADE DE SALVADOR 


\section{IDARAÍ SANTOS DE SANTANA}

IDALICE DEIRÓ NORONHA

\section{A TRAJETÓRIA DA EDUCAÇÃO DE JOVENS E ADULTOS E A EDUCAÇÃO INCLUSIVA NA CIDADE DE SALVADOR}

Trabalho de Conclusão de Curso, sob a forma de Artigo Científico, apresentado à Facultad Interamericana de Ciencias Sociales como parte do requisito para obtenção do grau de Mestrado em Ciências da Educação.

Orientador: Prof. Dr.César Costa Vitorino

Assunção - Paraguai

2020 


\title{
A TRAJETÓRIA DA EDUCAÇÃO DE JOVENS E ADULTOS E A EDUCAÇÃO INCLUSIVA NA CIDADE DE SALVADOR
}

\author{
Idaraí Santos de Santana ${ }^{1}$ \\ Idalice Deiró Noronha²
}

\begin{abstract}
RESUMO
Desde o período da colonização do Brasil até os dias atuais, inúmeras foram as investidas do governo no sentindo de alfabetizar os jovens e adultos, através de campanhas e programas para erradicar o analfabetismo no país, assim, objetivou-se em analisar a importância da Educação de Jovens e Adultos no processo de aprendizagem, assim como a contribuição da escola para no processo de aprendizagem dessa população alvo. A Educação de Jovens e Adultos surgiu na época do Brasil Colônia, sendo que, as aulas eram ministradas por jesuítas. E com o passar dos anos, a educação de jovens e adultos foi evoluindo com a criação de campanhas e programas em prol do aprendizado dos educandos. A Educação para Jovens e Adultos necessita de políticas públicas que resgatem o direito à cidadania, a dignidade, ao respeito, a valorização dos educandos e dos educadores, como forma de garantir sua inserção na sociedade, acesso integral à aprendizagem e ensino, ao conhecimento e a permanência na escola com direito a materiais didáticos adequados, fardamento, mobílias em perfeito estado e merenda escolar de qualidade.
\end{abstract}

Palavras-chave: Educação. Políticas Públicas. Jovens. Adultos.

\begin{abstract}
From the period of colonization of Brazil to the present day, countless efforts were made by the government to educate young people and adults, through campaigns and programs to eradicate illiteracy in the country, thus aiming to analyze the importance of Education Youth and Adults in the learning process, as well as the school's contribution to the learning process of this target population. Youth and Adult Education emerged at the time of Colonial Brazil, and the classes were taught by Jesuits. And over the years, the education of young people and adults has evolved with the creation of campaigns and programs in favor of the students' learning. Education for Youths and Adults needs public policies that rescue the right to citizenship, dignity, respect, valuing students and educators, as a way to guarantee their insertion in society, full access to learning and teaching, knowledge and the permanence in school with the right to adequate teaching materials, uniforms, furniture in perfect condition and quality school meals.
\end{abstract}

Palavras-chave:Education. Publicpolicy. Young. Adults.

\footnotetext{
${ }^{1}$ Graduada em Ciências Estatísticas pela Escola Superior de Estatística da Bahia - ESEB (2002); Especialista em Metodologia do Ensino, Pesquisa e Extensão em Educação pela Universidade Estadual da Bahia - UNEB (2004); Licenciada em Matemática pela Faculdade de Ciências Educacionais - FACE (2007); Professora de Matemática e atualmente Mestranda em Ciências da Educação pela Facultad Interamericana de Ciências Sociales - FICS.

${ }^{2}$ Graduada em Pedagogia, com habilitação em Supervisão Escolar, naFaculdade de Educação da Bahia (FEBA) no ano 2002; Especialista empsicopedagogia na Faculdade São Bento da Bahia, no ano de 2007; Licenciada em História pela Faculdade de Tecnologia e Ciências-FTC noano de 2011; Mestra em Ciências da Educação pela Facultad Interamericana de Ciências Sociales - FICS, no ano de 2019; Especialistaem Educação de Jovens e Adultos e, em Educação Especial com ênfase emDeficiência intelectual, Física e psicomotora, pela faculdade de EducaçãoSão Luís no ano de 2020; professora da Rede Municipal de Ensino.
} 


\section{INTRODUÇÃO}

O interesse em desenvolver sobre este tema surgiu, devido uma das autoras ser professora da Educação de Jovens e Adultos (EJA) e presenciar no ambiente laboral as constantes queixas dos alunos, ao dizerem que não tem um material didático de acordo às suas necessidades, um fardamento, um mobiliário adequado, uma merenda digna e de qualidade e que "vivem das sobras do turno anterior".

Essas constantes queixas, nos fizeram refletir, ao ponto de surgir o interesse em pesquisar sobre o tema políticas públicas voltadas para a educação de Jovens e Adultos, para a formação de professores, como também, sobre a política realizada no sentido de manutenção e conservação da escola no que tange aos aspectos físico e pedagógico, para que se tenha uma escola alinhada e de qualidade.

Considerando que a EJA é uma modalidade de ensino que, prevê a inserção dos estudantes jovens e adultos no ambiente escolar, possibilitando-o o ensino; oportunidades mais igualitárias, oportunizando para essas pessoas o acesso a novas formas de trabalho e cultura; e a função qualificadora que busca viabilizar à educação permanente, com base no caráter incompleto do ser humano, esta modalidade vem exigindo que os professores das escolas mudem suas práticas.

Embora se saiba que, desde o período da colonização do Brasil aos dias atuais, inúmeras foram as investidas no sentido de alfabetizar jovens e adultos, com o desenvolvimento de campanhas e programas para erradicar o analfabetismo no país. Cabe mencionar que, embora muitas destas não terem vingado, tantas outras deram certo, no entanto por pouco tempo, necessitando de uma reformulação.

Assim, o desenvolvimento deste estudo terá, inicialmente, uma abordagem das concepções políticas e as realidades do EJA, discorrendo sobre sua história, os tipos de educação existentes e os programas e campanhas públicas voltadas para a educação de jovens e adultos. Logo, será abordado as competências dos professores para se trabalhar na EJA, descrevendo sobre a gestão por competência e a competência profissional dos educadores. Por fim, será abordado as contribuições de Anísio Teixeira e Paulo Freire para a Educação de Jovens e Adultos. 
Dentro desse contexto, este artigo se objetiva em analisar a importância da Educação de Jovens e Adultos no processo de aprendizagem, assim como a contribuição da escola para no processo de aprendizagem dessa população alvo.

\section{EJA: CONCEPÇÕES POLÍTICAS E REALIDADES}

\section{HISTÓRICO DA EJA}

A Educação de Jovens e Adultos surgiu na época do Brasil Colônia, sendo que, eram ensinados aos povos indígenas a arte através dos trabalhos manuais, que era ministrada por jesuítas que aprendeu a língua desse povo para assim poder educá-los, além do funcionamento da economia colonial. Ao mesmo tempo que os jesuítas ministravam a educação formal e religiosa para as crianças, educavam também os adultos.

Na época do Brasil Colônia, a prioridade nos estudos era dada às crianças, por entenderem que formariam a nova geração católica e poderiam se tornar agentes multiplicadores diante do seu povo, no entanto, isso não foi impedimento para que os adultos fossem educados também, porém, dentro de um processo mais lento.

A intensa mobilização por parte dos jesuítas no processo de educar, era algo restrito aos homens indígenas. E não há registro da educação e/ou alfabetização de mulheres. Era percebido também, no período colonial, que não havia nenhum interesse por parte do governo em institucionalizar a escola, pois, nessa época, não foi constatado iniciativas significativas.

Já no período Imperial essa preocupação se tornou forte no Brasil, sendo a Educação um direito o qual tem como referência a Declaração Universal dos Direitos Humanos (ONU) de 1948 e a Constituição da República Federativa do Brasil de 1988. Isso quer dizer que, as situações as quais para igualização dos desiguais se faça necessário tratamento desigual, o que sem dúvida é o caso da Educação de Jovens e Adultos, que demanda um tratamento diverso ao atribuído à educação dita regular, em virtude da dívida histórica para com a educação do(a) estudantetrabalhador(a) (CAPUCHO, 2012, p. 23).

Essa falta de comprometimento por parte do governo na época do Brasil Colônia induziu a pensar que investir na educação de adultos, era algo não 
interessante, e pelo fato de se pensar que a educação criaria indivíduos perigosos, a classe dominante da época viu a educação dos adultos como desnecessária e até "prejudicial" à felicidade dos trabalhadores das classes pobres e que estes deveriam aceitar a posição à qual foram destinados na sociedade (CRUZ; GONÇALVES; OLIVEIRA, 2012, p. 01).

Um dos precursores da Educação de Jovens e Adultos no Brasil lutou pelo fim da educação elitista, pois, em seu pensamento a educação deveria ser democrática e libertadora. E partindo dessa luta, o EJA viveu um processo de amadurecimento que veio transformando a compreensão que dela tínhamos há poucos anos atrás e pode ser melhor percebida quando a situamos hoje como Educação Popular (FREIRE, 2001, p.16).

A Educação popular, como uma proposta de ensino, valoriza o saber prévio do povo e suas realidades culturais, se transformou para educandos e educadores, em um processo de reflexão e militância, no qual, vários docentes e grupos populares descobriram que através desse movimento (proposta) é possível pensar em uma educação libertadora, pois:

A Educação de Jovens e Adultos (EJA) é um campo carregado de complexidades que carece de definições e posicionamentos claros, é um campo político, denso e carrega consigo o rico legado da Educação Popular (ARROYO, 2001, p.7).

E dentro desse campo complexo, o educando se constitui como sujeito, através da construção de novas aprendizagens, por meio de um olhar crítico, que facilita o seu movimento no contexto ao qual está inserido, ou seja, sua comunidade. Permite também, que seja desenvolvido no educando o estímulo, o diálogo, uma participação mais consciente, uma melhor leitura da realidade social, política e econômica, à medida que cria no sujeito através do conhecimento adquirido a consciência cidadã.

Assim, a Educação popular utiliza o conhecimento da comunidade como subsídio para a construção de novos saberes, valorizando os sujeitos envolvidos no processo de educar, sendo que sua aplicação é mais comum em Instituições socioeducativas, em aldeias indígenas e no ensino de jovens e adultos. 


\section{DEFINIÇÃO DE EDUCAÇÃO DE ADULTOS, EDUCAÇÃO POPULAR, EDUCAÇÃO NÃO FORMAL E EDUCAÇÃO COMUNITÁRIA}

Para uma maior compreensão e clareza do tema em questão que é a itinerância de um sujeito da EJA no processo de Ensino Aprendizagem, é necessário entender a definição de termos como Educação de Adultos, Educação Popular, Educação não Formal e Educação Comunitária, que muitas vezes por falta do conhecimento são usados erroneamente.

A Educação de Adultos consiste em educar adultos que em algum momento de sua vida concluíram ou foram impedidos de concluir a educação formal. A mesma tem como propósito, envolver jovens e adultos estudantes, em atividades sistemáticas, ou seja, contínuas onde os educandos serão inseridos em um ambiente acolhedor e serão motivados para o desenvolvimento da aprendizagem, para a conquista de habilidades, atitudes e valores, partindo de um pressuposto de que eles querem e podem aprender e que são capazes e dispostos em arcar com a responsabilidade de sua aprendizagem.

A Educação Popular é a arte de educar através dos saberes do povo, valorizando a realidade cultural na construção de novos saberes. É pautada em um olhar crítico que facilita a ampliação da comunidade em que o estudante está inserido, proporcionando através desse olhar crítico o estímulo ao diálogo e a participação na comunidade, possibilitando a construção de uma formação social, política e econômica.

Por sua vez, a Educação não formal é aquela que acontece fora do sistema formal de ensino, complementando-se a este. É um método organizado onde os resultados não são avaliados formalmente. Nela, são trabalhados valores essenciais à formação humana, dando ao estudante subsídios para a formação do cidadão, pois, nela são trabalhados pontos que desenvolve no ser humano um olhar voltado para a melhoria da sua qualidade de vida e autoestima, e através desse entendimento por parte do cidadão, capacita-o para os mais diversos espaços da sociedade.

A Educação comunitária, no entanto, refere-se à educação que envolve vários programas sociais, voltados para as populações de baixa renda. Abarca, na maioria das vezes, uma população organizada, liderada em muitos casos por líderes 
comunitários, como também por financiadoras e tem como meta educar para a cidadania.

Destaca-se também, a importância de se analisar os diversos programas que foram criados com o intuito de alfabetizar jovens e adultos, pois, muitos deles não deram certo, outros foram reformulados. Mas os erros em relação aos programas ainda persistem, porque não existe por parte do governo, uma política de inclusão voltada para a educação de jovens e adultos, onde os mesmos possam se sentir amparados e valorizados.

Nesse sentido, visando corrigir ou amenizar essas perdas irreparáveis, inúmeras foram as investidas do governo no sentido de alfabetizar jovens e adultos, com a criação de diversos programas e campanhas.

\section{CAMPANHAS E PROGRAMAS PARA A EDUCAÇÃO DE JOVENS E ADULTOS}

Dentre as campanhas e os programas, destacam-se o Instituto Nacional de Estudos Pedagógicos (INEP) e também o Centro Brasileiro de Pesquisas Educacionais (CBPE) desdobrando-se em vários Centros Regionais. Criado no dia 13 de janeiro de 1937, onde inicialmente recebeu o nome de Instituto Nacional de Pedagogia.

No ano seguinte, em 1938, foi que o INEP iniciou realmente os seus trabalhos, quando foi publicado o decreto lei $\mathrm{n}^{-}$580, que regulamentou a organização e a estrutura da Instituição. A partir dessa organização e estruturação teve o seu nome modificado para Instituto Nacional de Estudos Pedagógicos tendo como diretor-geral do órgão o professor Lourenço Filho.

Vale destacar que a Campanha de Educação de adolescentes e Adultos (CEAA), foi um movimento em benefício da Educação de Jovens e Adultos, que surgiu em 1947 e se ampliou até o fim da década de 1950 cuja influência foi marcante por criar uma infraestrutura nas duas outras campanhas organizadas pelo Ministério da Educação e Cultura, a Campanha Nacional de Educação Rural (1952), que compreendia as ações dos Ministérios da Educação, da Agricultura e da Saúde.

A Campanha de Educação Rural foi coordenada por Artur Rios, e tinha a visão de que a sala de aula não era o suficiente para que o aluno aprendesse. Partindo desse princípio, foram realizadas ações educativas junto às comunidades rurais, no sentido de trabalhar a educação sanitária, a higiene, a saúde e a 
introdução de algumas técnicas agrícolas, dando ênfase a realização de campanhas como a de água filtrada, fossa sanitária e também atendimento as mães no pré e pós-natal. No entanto, sobreviveu por pouco tempo, devido a falta de verbas, o que contribuiu para o seu insucesso.

O Sistema Rádio Educativa Nacional (SIRENA) outra campanha importante, criada em 1957 para a educação de adultos, tinha como apoio a Igreja Católica que ofereceu a estação de rádio de sua propriedade, para alfabetizar os adultos através de gravações radiofônicas. Um segundo momento dessa campanha foi a construção da cartilha, que vai de 1959 até 1964 e que foi patrocinado pelo Governo Federal.

Em contrapartida existiram também ações repressivas, como programas de caráter conservador, como por exemplo: a Cruzada de Ação Básica Cristã (ABC) e oMovimento Brasileiro de Alfabetização (MOBRAL) em 1967, esta última, só fora instituído no período da ditatura militar, em 1970, com o Programa de Alfabetização Funcional (PAF) e com a expansão da industrialização, e consequente avanço do capitalismo, pois o país precisava de mão obra qualificada, motivo pelo qual ampliou-se a escolarização com o intuito de diminuir o analfabetismo entre homens e mulheres.

Ao ser criado, o MOBRAL mobilizou o País através da campanha "Você também é responsável", que incentivava a participação da sociedade no novo projeto de educação. Essa campanha tinha como objetivo alfabetizar os adultos, mas por conta da dificuldade em conseguir um número de adultos suficientes, foi lançado uma proposta do Mobral infanto-juvenil, que passou a atender menores de 7 a 15 Anos.

Todos os responsáveis pelo Mobral confirmam a existência de uma política de incorporação de menores de 15 anos às classes do movimento desde o início do programa e buscam justificá-la de algum modo. Marcos Candau confirma que, desde a primeira hora, o Mobral aceitou rotineiramente em suas classes crianças de 10,11,12, 13 e 14 anos (PAIVA, 1982, p. 51-72).

No início do programa, foram convidados voluntários de todo o Brasil, dentre eles alfabetizadores, monitores e supervisores, que trabalhavam gratuitamente para a instituição. O MOBRAL ampliou-se firmando acordos com instituições privadas e órgãos governamentais, a saber: Departamento de Educação Básica de Adultos; SENAC eSENAI;Centro Brasileiro de TV Educativa (FCBTVE);Fundação Padre Anchieta;CNER, Fundação Educar e Movimento de Alfabetização MOVA; PAS 
(Alfabetização Solidária); Programa Nacional de Educação na Reforma Agrária (PRONERA); e Programa Brasil Alfabetizado(PBA).

Outro programa de suma importância para a educação é o programa Brasil alfabetizado criado em 2003 e tem como objetivo a Educação de Jovens e Adultos (EJA) e trabalha com uma população acima de 15 anos. O programa tem como preferência cidades cujo índice de analfabetismo é alto, de maneira especial a Região Nordeste. E para participar do programa é necessário que a Prefeitura e o Estado aderissem ao Sistema Brasil Alfabetizado.

A posição doMinistério de Educação e Cultura (MEC), ao dizer que, qualquer cidadão com o nível médio completo pode se tornar um alfabetizador, nos remete a refletir sobre que tipo de educação formadora e que tipo de profissional foi colocado nesse período em que o programa foi lançado.

Outro programa foi o Programa Nacional do Livro Didático para a Alfabetização de Jovens e Adultos (PNLDEJA) que agrupou o Programa Nacional do Livro Didático para a Alfabetização de Jovens e Adultos (PNLA), e expandiu o atendimento, inserindo o primeiro e o segundo segmentos de EJA, que correspondem aos anos iniciais e finais do ensino fundamental.

O PNLDEJA trabalha com a distribuição de obras e coleções do Programa Brasil Alfabetizado que atende a educandos e educadores da EJA. A partir de então, foi criado o Programa Nacional de Inclusão de Jovens (Pro Jovem) na modalidadeURBANO com o objetivo de elevar a escolaridade de jovens entre $18 \mathrm{e}$ 29 anos que tenham o conhecimento da leitura e da escrita, mas, que não concluíram o ensino fundamental na idade apropriada, para assim, inseri-lo no mercado de trabalho e possibilitar a ele o exercício da cidadania.

O propósito desse programa é concluir o ensino fundamental, integrando a Educação de Jovens e Adultos à qualificação profissional, além de curso sobre ações comunitárias objetivando a cidadania. O curso tem uma duração de 18 meses, sendo realizado tanto presencialmente como a distância, e ainda, os alunos desse programa recebem uma bolsa mensal de $R \$ 100,00$.

O Movimento de Educação de Base (MEB) nasceu de uma proposta feita por Dom Távora ao recém-eleito presidente Jânio Quadros e surgiu como um projeto de educação de base para o meio rural, a ser desenvolvido por meio das escolas radiofônicas. Tinha como meta alfabetizar milhares de pessoas em um período de cinco anos. Isto foi uma sugestão que apareceu para beneficiar àquelas pessoas 
que não tinham concluído a escolarização na idade certa. Incialmente as áreas de atuação seriam o Nordeste, Centro-Oeste e o Norte, mais tarde ampliadas para o estado de Minas Gerais.

Com base em tudo que foi colocado sobre Programas e Campanhas para Educação de Jovens e Adultos, é importante refletir sobre que tipo de política está sendo desenvolvida no sentido de resgatar o direito à cidadania, a dignidade, 0 respeito, a valorização dos alunos da EJA para garantir o acesso ao conhecimento, a permanência na escola e a sua aprendizagem que por muito anos foi negada.

As políticas de educação representadas pelo poder público, deveriam proporcionar a esses educandos a sua inserção na sociedade, dando-lhes a igualdade de oportunidades que só através do saber adquirido, permitirá o seu desenvolvimento pessoal e profissional para assim, serem integrados ao coletivo.

No cenário educacional brasileiro, as marcas da precariedade e da improvisação no ensino são históricas, não sendo uma exclusividade da EJA, isso quer dizer que atinge aos diversos seguimentos da educação, porque na verdade, não existe uma política educacional, no sentido de atender com eficiência e qualidade.

Em muitos casos, quem investe em sua própria formação, como também, para que o aluno da EJA permaneça na escola é o professor, que por sua vez, lançará mão da sua experiência de vida, para assim, desenvolver um trabalho de alfabetização, tendo como referência a proposta de ensino desenvolvida pelo educador Paulo Freire no seu processo de alfabetizar jovens e adultos.

É nesse sentido, e por entender a realidade do aluno, que o professor da EJA utiliza e valoriza o conhecimento através da vivência que cada aluno possui. Vale lembrar que esses aspectos envolvem o cognitivo, o motor e o afetivo, sendo assim, o professor é responsável na formação desse ser que se encontra em formação, e a esse professor, é atribuído diversas funções, onde são desempenhados diversos papéis, a saber:

Conhecimento dos processos de desenvolvimento humano (em termos de exemplificação e aplicabilidade);

Conhecimentos dos processos de aprendizagem (em termos de exemplificação e aplicabilidade);

Compreensão das influências do ambiente sócio-econômico-cultural sobre o educando;

Compreensão e sensibilidade para as diferenças individuais dos educandos; Habilidade em manter um relacionamento humano eficaz;

Habilidade em comunicar-se clara e eficazmente;

Habilidade em resolver problemas de sala de aula; 
Habilidade em motivar seus alunos;

Habilidade em selecionar e desenvolver formas de desempenho adequados ao processo de ensino;

Habilidade em trabalhar cooperativamente;

Interesse em trabalhar com crianças e em função de suas necessidades (LUCK, 2003, 14).

As habilidades citadas acima, já fazem parte do currículo do professor que almeja o desenvolvimento do seu aluno nos diversos aspectos: Nós, enquanto professores, não podemos esperar pelos cursos de formação, porque em muitos casos, o que é abordado nesses cursos, pouca interessa para a formação do professor e automaticamente para a formação dos alunos da EJA.

Quando se discute sobre a formação do professor para trabalhar com educação de jovens e adultos, é interessante salientar que é algo de grande relevância, pois, em sua maioria são profissionais que têm criatividade $e$ compromisso, mais, em alguns casos, existem educadores que não apresentam habilitação específica.

O que muitos educadores buscam é construir uma escola de qualidade que atenda às necessidades e os anseios principalmente das classes populares, pois esta é a mais prejudicada pelas desigualdades sociais. Uma escola que inclua e não exclua, pois, para Capucho (2012, p.71) "o debate em torno de uma educação inclusiva favorece para que a escola seja compreendida em seu potencial democrático, como espaço de participação e aprendizagem".

Nesse sentido e em relação ao que foi exposto acima, cabe a escola enquanto espaço de convivência, acolhimento e desenvolvimento do educando, aluno da EJA e ao professor, através do Projeto Político Pedagógico construir um planejamento que seja acessível ao aluno, onde contemple ações que possam ser desenvolvidas, valorizando o conhecimento do estudante (leitura de mundo), desmistificando crenças e preconceitos, superando as barreiras impostas pela sociedade.

\section{COMPETÊNCIAS PARA TRABALHAR NA EJA}

\section{ENQUADRAMENTO TEÓRICO DO TERMO “COMPETÊNCIA"}

O termo competência tem sido perspectivado ora como atribuição, ora como qualificação, ora como traço/característica pessoal, ora como comportamento/ação, chamando a atenção ora para características extra pessoais (perspectiva das 
atribuições e das qualificações), ora intrapessoais (perspectiva dos traços/características pessoais) e/ou comportamentais(CEITIL, 2006).

Em Educação o conceito de competência tem surgido como alternativa a capacidade, habilidade, aptidão, potencialidade, conhecimento ou savoir-faire. É a competência que permite ao sujeito aprendente enfrentar e regular adequadamente um conjunto de tarefas e de situações educativas. Aqui em alusão a esta pesquisa, deve-se entender "aprendente" como o funcionário não docente que se propõe a aprender, quando possibilitado a este a capacitação e formação, podendo este vir, junto às suas atividades, colocar em prática o conteúdo apreendido no âmbito escolar, em consonância com as habilidades intrínsecas a cada um.

Neste sentido, competência tende a ser um constructo teórico que se supõe como uma construção pessoal, singular, específica de cada um. É única e pertence, exclusivamente, à pessoa, exprimindo-se pela adequação de um indivíduo a uma situação (REY; CARETTE; DEFRANCE et al., 2005).

Reportando-se a Roldão (2003), este mostrou que a competência emerge quando, perante uma situação, o sujeito é capaz de mobilizar adequadamente diversos conhecimentos prévios, selecioná-los e integrá-los de forma ajustada à situação em questão. Desta forma, a competência exige apropriação sólida e ampla de saberes, de modo a permitir ao sujeito que os convoque (de forma ajustada) quando se encontra face a diferentes situações e contextos.

Competência recorre, desta forma, às noções, conhecimentos, informações, procedimentos, métodos e técnicas, onde está relacionado, também ao processo de formação para o desempenho das funções. Assim. Cruz (2001) definiu competência como um conceito que acolhe saberes, atitudes e valores, abarcando o domínio do self (saber-ser), o domínio cognitivo (saber formalizado) e o domínio comportamental (saber-fazer).

Tanto Cruz (2001) quanto Alves (2005), comungam do mesmo pensamento onde entendem que a competência está na identificação da capacidade que as pessoas desenvolvem para articular, relacionar os diferentes saberes, conhecimentos, atitudes e valores; como uma ação cognitiva, afetiva, social que se torna visível em práticas e ações que se exercem sobre o conhecimento, sobre o outro e sobre a realidade.

Constitui-se por um conjunto de saberese de atitudes que podem ser mobilizadas e traduzidas em performances que Cruz (2001, p. 31) afirma que: "A 
competência é agir com eficiência, utilizando propriedade, conhecimentos e valores na ação que desenvolve e agindo com a mesma propriedade em situações diversas".

Para Perrenoud (1999), uma competência traduz-se na capacidade de agir eficazmente perante um determinado tipo de situação, apoiada em conhecimentos, mas sem se limitar a eles. É um saber em uso que exige integração e mobilização de conhecimentos, processos e predisposições que, ao incorporarem-se uns nos outros, vão permitir ao sujeito fazer, pensar e apreciar. Constitui a faculdade de mobilização de recursos cognitivos, com vista à resolução com pertinência e eficácia de uma série de situações (GENTILLE; BENCINI, 2010).

Nestas enunciações, é possível encontrar diferentes componentes das competências: saber-saber, saber-fazer, saber-ser. Definir competência através de cada uma destas componentes pode ser, no entanto, uma tentação perigosa, uma vez que os saberes fazem parte da competência, mas não se podem confundir com ela; as competências são descritas como ações, mas não é o fato de descrever as ações que explica ou que possibilita a ação ou o êxito; as competências estão diretamente relacionadas com o contexto e o saber-ser não tem implícito esse contexto (PERENOUD, 2001).

A competência integra e coordena um conjunto de esquemas (de percepção, pensamento, avaliação e ação) que sustém inferências, antecipações, transposições analógicas, generalizações, probabilidades, recolham de informação pertinente, tomada de decisão. A competência integra, assim raciocínios, decisões conscientes, inferências, hesitações, ensaios e erros para se ir automatizando e constituindo-se num esquema complexo (PEREIRA, 2005).

O entendimento, então, é de que a competência se apropria, assim, da ação, preexiste e exige recursos e meios para promover a mobilização. Se não há recursos a mobilizar não há competência, e se há recursos, mas não é possível mobilizá-los a tempo, é como se não existissem, conforme descreveu Perrenoud (2001; 2005).

\section{GESTÃO DA COMPETÊNCIA}

Acompetência é baseada no CHA, (C) conhecimentos, (H) habilidades, competências técnicas, e as $(A)$ atitudes e competências comportamentais que uma 
pessoa possui. O conhecimento tem relação com a formação acadêmica, se trata do conhecimento teórico. A habilidade está ligada ao prático, a vivência e ao domínio do conhecimento. Já a atitude representa as emoções, os valores e sentimentos das pessoas, isto é, o comportamento humano.

A gestão por competências direciona sua ação prioritariamente para o gerenciamento da lacuna de competências eventualmente existente na organização ou equipe, procurando eliminá-lo ou minimizá-lo. A ideia é aproximar ao máximo as competências existentes na organização daquelas necessárias para atingir os objetivos organizacionais.

A gestão por competências representa uma alternativa aos modelos gerenciais tradicionalmente utilizados nas organizações e propõe-se a orientar esforços para planejar, captar, desenvolver e avaliar, nos diferentes níveis da organização (individual, grupal e organizacional) as competências necessárias para alcançar seus objetivos.

Inicialmente, as transformações nas organizações, acontecidas a partir da década de 1990, segundo Furtado e Neto (2007), ocasionaram profundas mudanças nas relações de trabalho, mais notadamente graças ao aumento da competitividade entre os mercados, exigindo delas a reestruturação produtiva e a necessidade de novas tecnologias.

Anteriormente, Cardoso (2009, p. 9), afirmou que a atividade produtiva adquiriu novos contornos: "[...] cujas principais características foram as mudanças na cultura organizacional e das práticas de gestão das empresas para enfrentar os novos paradigmas da qualidade, produtividade e competitividade internacional". Nessa perspectiva, o entendimento é de que as transformações que impactam as organizações dizem respeito aos pressupostos voltados, para as características do trabalho, as estruturas organizacionais e as características de gestão.

O conceito de competência começou a ser construído sob a perspectiva do indivíduo, e conforme McClelland (1973, apud FLEURY e FLEURY, 2001, p. 45) no início da década de 1970 menciona que:

A competência se relaciona ao desempenho superior de uma pessoa na realização de uma tarefa, salientando ser a competência uma característica subjacente a uma pessoa que pode ser relacionada com desempenho superior na realização de uma tarefa ou em determinada situação. Diferenciava, assim, competência de aptidões 
(talentos naturais da pessoa, que podem vir a ser aprimorados), de habilidades (demonstrações de talentos particulares na prática) e de conhecimentos (o que a pessoa precisa saber para desempenhar uma tarefa).

Mais tarde, já nos anos 2000, Zarifian (2001, p. 66), avançou na conceituação sobre a competência, relacionando a competência à qualificação, mais precisamente, na capacidade do indivíduo em ir além, em determinadas atividades, procurando compreender, dominar e se responsabilizar pelas novas situações profissionais, promovendo alterações no comportamento dos trabalhadores e em sua relação com a organização, afirmando que:

A competência [...] é uma combinação de conhecimentos, de saber fazer, de experiências e comportamentos que exerce em um contexto preciso. Ela é constatada quando de sua utilização em situação profissional, a partir da qual é passível de validação.

O entendimento dessa assertiva é de que a competência pode ser compreendida como um conjunto de elementos voltados para o conhecimento (teórico e/ou acadêmico), prática ("experiência") e comportamento, no dia-a-dia das atividades profissionais exercidas pelo trabalhador e que são "validadas", a partir do momento que consideradas funcionais.

Percebe-se, uma relevância no estudo da competência, uma vez queexistem algumas habilidades, que são imprescindíveis ao profissional da educação, que passa a compreender a importância da formação continuada e que é essencial buscar, através educação continua e de novas referências, no sentido de aprender mais, levando-o a entender, que a competência pressupõe uma ação, que agrega valor diante de novas situações, possibilitando ao indivíduo se tornar protagonista de suas próprias ações.

Importa destacar que o conceito de competência se aproxima do conceito de saber tácito, síntese de conhecimentos esparsos e práticas laborais vividas ao logo de trajetórias que se diferenciam a partir das diferentes oportunidades e subjetividades dos trabalhadores. Estes saberes não se ensinam e não são passíveis de explicação, da mesma forma que não se sistematizam e não identificam suas possíveis relações com o conhecimento teórico (KUENZER, 2000).

As mudanças ocorridas no mundo do trabalho, com a progressiva perda de hegemonia do taylorismos/fordismo e de suas formas de fragmentação a partir da 
mediação da microeletrônica, tornam insuficiente este tipo de competência para os trabalhos que não se precarizaram e que se constituem no núcleo estável do trabalhador coletivo, ainda com direitos e condições razoáveis de vida e de trabalho, apesar da tendência à intensificação; para poucos, portanto, já aqui se configurando uma das dimensões ideológicas da proposta da "pedagogia das competências", apresentada como universal.

Embora, a tendência dos processos, mediados pela microeletrônica, exatamente em face de sua complexidade, suponham, uma relação do trabalhador com o conhecimento materializado nas máquinas e equipamentos como "usuário", demandam o desenvolvimento de capacidades cognitivas complexas, em particular as relativas a todas as formas de comunicação, ao domínio de diferentes linguagens e ao desenvolvimento do raciocínio lógico-formal, competências estas desenvolvidas através de relações sistematizadas com o conhecimento através de especificamente pedagógicos disponibilizados por escolas ou por cursos de educação profissional.

No entendimento de que, na classe burguesa estas competências se desenvolvam desde as relações sociais e familiares que viabilizam o desenvolvimento das linguagens, do raciocínio e o acesso à produção cultural, mesmo assim não se prescinde da educação escolar.

Já para os que vivem das diferentes formas de trabalho, onde a precarização econômica dificulta o acesso à produção cultural dominante, a escola passa a ser espaço fundamental para a aquisição dos conhecimentos que permitam o desenvolvimento das competências requeridas para a inclusão na vida social e produtiva e agora, em face da mediação das novas tecnologias que tornam o trabalho cada vez mais abstrato no atual regime de acumulação, assume novas dimensões.

Nessa perspectiva, o autor propõe uma nova epistemologia da prática e da ética, a qual se embasa nos conceitos de conhecimento na ação e reflexão na ação. O conhecimento na ação é o componente que está diretamente relacionado com o saber-fazer, é espontâneo, implícito e que surge na ação, ou seja, um conhecimento tácito. Sendo assim, a reflexão se revela a partir de situações inesperadas produzidas pela ação e nem sempre o conhecimento na ação é suficiente.

São três tipos distintos de reflexão: a reflexão sobre a ação, a reflexão na ação e a reflexão sobre a reflexão na ação. A reflexão sobre a ação consiste em se pensar retrospectivamente sobre o que se faz, almejando descobrir como o ato de 
conhecer-na-ação pode ter contribuído para um resultado inesperado. A reflexão-naação consiste em refletir no meio da ação, sem interrompê-la.

O pensamento conduz a dar nova forma ao que se está fazendo e no momento em que se faz, possibilita interferir na situação em desenvolvimento. Diferentemente, a reflexão sobre a reflexão-na-ação repousa no ato de pensar sobre a reflexão-naação passada, consolidando o entendimento de determinada situação e, desta forma, possibilitando a adoção de uma nova estratégia.

Importante refletir sobre a importância de se pensar na necessidade de especialistas, que possuam a formação com habilidades e competências, capaz de atender as demandas do mercado de trabalho. Contudo, entende-se que este profissional nem sempre encontrará em seu arsenal as respostas certas para cada situação. Pois são situações diferentes, portanto exigem respostas díspares (SCHON, 2000).

A utilização do termo talento artístico profissional é para referir-se aos tipos de competências e, esse, deve ser ensinado por meio da reflexão na ação. Não sendo essas competências fáceis de conseguir explicá-las na realidade, sem incorrer na possibilidade de fragilizar, ou omitir o que de fato se sabe fazer. Este saber fazer se sente e não se explica, pois quando um docente consegue ensinar o seu aprendiz a se apropriar de uma habilidade perpassando por tal talento e não pela questão da teoria, fez uma grandiosa ação (Ibidem).

Vale mencionar que, não diferente esse ensinamento também se caracteriza como uma ação elevada quando propicia a formação, pois a expressão conhecer na ação, para o citado autor, são conhecimentos que são ações perceptíveis, observáveis, contudo, a explicação não corresponde ao fato. É o processo tácito, implícito. Diferentemente, a reflexão na ação leva a constatações, pois pensa criticamente sobre o que está fazendo e modificando as estratégias, se necessários.

\section{COMPETÊNCIA PROFISSIONAL}

Discutir competência profissional nos remete a um dos dilemas que sempre esteve posto para os processos educativos, e que agora, em face da mediação das novas tecnologias que tornam o trabalho cada vez mais abstrato no atual regime de acumulação, assume novas dimensões, sobretudo, no que diz respeito às competências profissionais (PERRENOUD, 2005). 
A competência profissional é às vezes superficial, outras vezes aprofundado, oriundo da experiência pessoal, do senso comum, da cultura partilhada em um círculo de especialistas ou da pesquisa tecnológica ou científica. Quanto mais complexas, abstratas, mediatizadas por tecnologias possibilita que se tenham mais conhecimentos e que estes sejam aprofundados, avançados, organizados e confiáveis (PERRENOUD, 2005).

A partir desta compreensão, o autor afirma que a construção de competências exige tempo, sendo este o dilema da escola não diferenciar o conhecimento tácito, derivado da articulação entre saberes diversos e experiência, ou conhecimento de senso comum, onde ciência e ideologia se mesclam, de conhecimento teórico; daí o dilema: é preciso tempo para que esta articulação se dê; ele não questiona, contudo,o tempo de permanência na escola, o espaço da escola, permite esta articulação.

A competência se sustenta em conhecimentos tácitos. É corrente entre eles, também, a clareza que a formação teórica é necessária, por que, em tese, melhora as condições de atuação; contudo, há outros fatores que intervém na capacidade de enfrentar situações de risco, que extrapolam a dimensão cognitiva, tais como a disposição para atuar, a estabilidade emocional, a capacidade de atuar em situações de stress, o comprometimento com o coletivo, e assim por diante.

$\mathrm{E}$, ainda, mantendo-se a discussão no domínio cognitivo, está presente a capacidade para articular a situação a ser enfrentada com outras situações que contiveram elementos similares, bem como a capacidade para articular conhecimentos teóricos a conhecimentos práticos, reafirmando a compreensão de que a simples existência de conhecimentos, sejam eles tácitos ou teóricos, não é suficiente para desencadear ações competentes.

Os seres humanos não vivem todas as mesmas situações. Eles desenvolvem competências adaptadas a seu mundo, que em grande parte se adquiri na escola. Tem-se que a ênfase trazida para as questões que envolvem a competência profissional, por Perrenoud (2005), está um exercício para identificar as competências fundamentais para a autonomia das pessoas, onde chegou a oito categorias, descritas abaixo (Quadro 1).

Quadro 1: Competências fundamentais para a autonomia das pessoas, segundo Perrenoud. 


\begin{tabular}{|c|c|}
\hline $\begin{array}{l}\text { 1. Saber identificar, avaliar e valorizar } \\
\text { suas possibilidades, seus direitos, seus } \\
\text { limites e suas necessidades }\end{array}$ & $\begin{array}{l}\text { 2. Saber formar e conduzir projetos e } \\
\text { desenvolverestratégias, individualmente } \\
\text { ou em grupo; saber analisar situações, } \\
\text { relações e campos de força de forma } \\
\text { sistêmica }\end{array}$ \\
\hline $\begin{array}{l}\text { 3. Saber analisar situações, relações e } \\
\text { campos de força de forma sistêmica }\end{array}$ & $\begin{array}{l}\text { 4. Saber cooperar, agir em sinergia, } \\
\text { participar de uma atividade coletiva e } \\
\text { partilhar liderança }\end{array}$ \\
\hline $\begin{array}{l}\text { 5. Saber construir e estimular } \\
\text { organizações e sistemas de ação } \\
\text { coletiva do tipo democrático }\end{array}$ & 6. Saber gerenciar e superar conflitos \\
\hline $\begin{array}{l}\text { 7. Saber conviver com regras, servir-se } \\
\text { delas e elaborá-las }\end{array}$ & $\begin{array}{l}\text { 8. Saber construir normas negociadas de } \\
\text { convivência que superem diferenças } \\
\text { culturais }\end{array}$ \\
\hline
\end{tabular}

Fonte: Elaboração própria (2020), adaptado de Perrenoud (2005).

O entendimento do autor é de que em cada uma dessas categorias, deveria ainda especificar concretamente grupos de situações. Por exemplo: saber desenvolver estratégias para manter o emprego em situações de reestruturação de uma empresa. Assim a formulação de competências se afasta, então, das abstrações ideologicamente neutras. Dessa forma, a unanimidade está ameaçada e reaparece a ideia que os objetivos da escolaridade dependem de uma escolha da sociedade.

Dentro desse contexto, entende-se que é inútil exigir esforços sobre humanos aos professores, se o sistema educativo não faz nada além de adotar a linguagem das competências, sem nada mudar de verdade. Mesmo porque para o desenvolvimento de competências é preciso, antes de tudo, que o professor trabalhe por problemas e por projetos, propor tarefas complexas e desafios que incitem os alunos a mobilizar seus conhecimentos e, em certa medida, completá-los. Isso pressupõe uma pedagogia ativa, cooperativa, aberta para a cidade ou para o bairro, seja na zona urbana ou rural.

Desse ponto de vista, se surgissem novas competências, não seria para responder a novas possibilidades técnicas, mas devido à transformação da visão ou das condições de exercício da profissão.Estas competências estarão tão mais presentes quanto mais ricas forem as experiências vividas, os conhecimentos adquiridos, o acesso às informações, as capacidades para mobilizar e transferir conhecimentos tácitos e teóricos, o que depende apenas em parte do domínio cognitivo, adentrando-se na esfera do domínio afetivo ou comportamental, 
expressão esta preferida pelos teóricos contemporâneos para fugir de uma suposta abordagem psicologista da questão.

\section{IMPORTÂNCIA DE ANÍSIO TEIXEIRA E PAULO FREIRE PARA A EJA}

Historicamente, os períodos da escola pública foi o jesuítico, sob o comando da Coroa. Importa, trazer à baila, o posicionamento de Paulo Freire sobre a questão da EJA, como contraponto ao posicionamento de Anísio Teixeira.

No período da década de 1960, de desenvolvimento das políticas sobre a EJA, as ideias de Paulo Freire foram muito divulgadas e amplamente aceitas. Paulo Freire enxergava que o desenvolvimento educativo das pessoas deve acontecer contextualizado às necessidades essenciais do cotidiano. O conteúdo a ser estudado deveria ser feito "com" elas e não "para" elas. Além disso, afirmava que as pessoas analfabetas não deveriam ser vistas como imaturas e ignorantes, pois o saber vai além do letramento e a experiência de vida de cada um carrega em si uma diversidade enorme de conhecimento.

Portanto, de acordo com Stephanou e Bastos (2005 apud STRELHOW, 2010, p. 53): "[...] não bastava ensinar a ler e escrever; era preciso contextualizar a alfabetização no processo de vida de cada sujeito, nas suas necessidades sociais, existenciais e materiais; na sua cultura e forma de perceber a si e o outro". A compreensão em torno dos ensinamentos de Freire era de que o problema do analfabetismo não era o único nem o mais grave da população: as condições de miséria em que vivia o não alfabetizado é que deveriam ser problematizadas.

Um dos resultados dramáticos, da combinação entre um mundo mergulhado no neoliberalismo e o avanço do direito à educação, tem sido a frustação diante da constatação de que os esforços por colocar a EJA na agenda dos governos não resultaram em avanços significativos. Tanto no Brasil, quanto no mundo, o número de analfabetos jovens e adultos diminui lentamente e os avanços na escolaridade desse grupo são tímidos. 
O dilema talvez resida justamente na consequência maior das políticas neoliberais: o aprofundamento das desigualdades sociais, cenário em que os potenciais educandos da EJA não poderiam mesmo ver seus direitos realizados.

Muitas críticas foram sendo feitas ao método de alfabetização adotado para a população adulta. Com as precárias condições de funcionamento das aulas e a pouca participação e frequência dos alunos, houve um declínio dos programas instalados pelo Governo, difundidos em diversas cidades brasileiras (SOARES, 1996).

Porém, dentre todas as delegações, uma obteve destaque, por ir além das críticas e apontar soluções para os problemas e dificuldades. A delegação de Pernambuco, da qual fazia parte Paulo Freire. O ensino freiriano era realizado através de uma comunicação dialógica entre o professor e o estudante e uma adequação do método às características das classes populares, a partir da vivência (BRANDÃO, 2002), onde nas salas de aula freirianas, os conteúdos e ações pedagógicas eram articulados de forma humanizada, com a finalidade de promover a libertação dos sujeitos.

Fica a observância, então, de que o método desenvolvido por Freire contribuiu na orientação das políticas curriculares, construindo um horizonte de possibilidades para a emancipação humana a serviço da transformação social. E, dentro dos ensinamentos de Paulo Freire, um novo entendimento foi apresentado para a questão da EJA, relacionando as problemáticas educacional e social.

Sobre essa questão, Soares (1996) se posicionou mencionando que o analfabetismo, que antes era apontado como causa da pobreza e da marginalização, passou a ser interpretado como efeito da miséria gerada por uma estrutura social não igualitária.

No ano de 1964, com o destaque que o pensamento de Paulo Freire atingiu no meio educacional, foi aprovado o Plano Nacional de Alfabetização, com a intensão de expansão por todo o país dos programas de alfabetização, sob a égide do método desenvolvido por Paulo Freire, onde para Lara (2010, p. 3) "Porém logo após essas medidas serem tomadas, essas ações foram interrompidas pela tomada do poder por parte dos militares e os seus promotores foram duramente reprimidos".

No período do governo militar que se iniciou no Brasil, as ações dos movimentos sociais e as medidas anteriores do governo foram substituídas por campanhas de alfabetização de cunho mais conservador nos propósitos e mais 
assistencialistas nos procedimentos, com a distribuição de alimentos para os alunos jovens e adultos. A nova política relacionada à ideia de educação do estado, pressionada pelos capitalistas, com o objetivo de promover o desenvolvimento econômico do país, assumia a ideologia tecnicista, cujo objetivo único era formar mão-de-obra operária.

Com o neoliberalismo crescente no país, as desigualdades sociais se alastravam criando-se um abismo cada vez maior entre os burgueses e operários, havendo ainda uma parcela da população que não tinha condições de sobreviver dignamente. A urbanização e a escassez dos serviços na zona rural, a explosão demográfica nos grandes centros urbanos refletia um aglomerado de pessoas pobres que viviam em ruas, morros e vielas, sem infraestrutura que lhes garantisse saneamento básico, educação, saúde, lazer e trabalho dignos.

Excluídos dos direitos sociais e humanos, não lhes bastavam uma sala de aula precária e uma cartilha. Era necessário um processo de conscientização política, para a superação da ingenuidade e fortalecimento destes sujeitos. Como forma de reduzir as desigualdades e tentar equacionar o problema da escolaridade da população adulta, o MEC criou novos programas.

Ficou notório que a educação sozinha não consegue promover a redução das desigualdades. Seria necessária uma ação conjunta das diversas instituições civis e governamentais, vindo a contemplar as dimensões econômicas, de trabalho, lazer, saúde, moradia e segurança, no entendimento de que sem as quais o sujeito não conseguirá sair da condição de excluído.

Observa-se que a proposta de Paulo Freire consistia na alfabetização dos excluídos, se diferenciando da proposta, descrita anteriormente, de Anísio Teixeira quando se propôs a promover uma educação formativa, profissionalizante dos jovens e adultos. Sua preocupação era para com os concursos públicos como forma de recrutar os profissionais da educação. Antes os cargos eram providos segundo interesses pessoais ou políticos. Anísio Teixeira entendia que o concurso exigiria a profissionalização do docente.

É importante mencionar que o papel de Anísio Teixeira, no campo das políticas públicas de educação, deu margem a uma "tecnocracia" pedagógica, ao considerar os aspectos técnicos da formação docente como condição necessária para a transformação do trabalho na educação, diferentemente da vertente defendida por Paulo Freire, que não menos importante, sua abordagem, nesta pesquisa, foi tão- 
somente, para descrever que sua pesquisa também foi importante no contexto que envolveu a EJA.

\section{METODOLOGIA}

Os trabalhos científicos pressupõem a utilização da metodologia de pesquisa que delimita e dá sentido à forma como o pesquisador lança mão para investigar, conhecer e, buscar os caminhos que o levarão a responder os seus objetivos. Em ciências sociais a metodologia de pesquisa pode ser de natureza qualitativa e/ou quantitativa, dependendo do objetivo a que o pesquisador se propõe.

A base conceitual adotada para descrever o caminho metodológico que desenvolveu esta pesquisa foi a partir das ideias de Flick (2013), sobretudo, quando afirmou que a pesquisa social tem sido marcada por estudos que valorizam o emprego de métodos quantitativos para descrever e explicar fenômenos.

A pesquisa em ciências sociais possui três correntes de pensamento contemporâneo com enfoques diferentes: o positivismo, a fenomenologia e o marxismo. Considerando-se que a pesquisa científica exige, entre outras características, a criatividade, a disciplina, a organização e a modéstia do pesquisador. Assim, para o objetivo proposto nessa dissertação, foram levados em conta os confrontos que a pesquisadora lidou, e lida, no decorrer de sua atividade como gestora educacional. Nesse sentido, a pesquisa em ciências sociais deve, entre outras coisas, suscitar o debate entre a sociologia positivista e outros tipos, de acordo com Goldenberg (1999).

O Positivismo isola o fenômeno, identifica, mede, qualifica sem a sua significação e base teórica. Todavia, perdeu importância, pois a prática da investigação se transformou numa atividade mecânica, onde a busca por resultados essencialmente estatísticos amarrou o investigado ao dado, ao estabelecer "relações estatisticamente significativas entre os fenômenos".

$\mathrm{Na}$ visão do contexto/situação do marxismo tem uma amplitude no campo estudado, observando as relações. A tradição no emprego da análise marxista da realidade fundada na filosofia do materialismo histórico e da luta de classes, no meio 
da pesquisa em educação, por exemplo, onde a complexidade do método dialético levanta sólidas barreiras diante dos pesquisadores.

Dentro desse conceito, para atingir o objetivo proposto, utilizou-se como metodologia a pesquisa bibliográfica, qualitativa e quantitativa, analisando e destacando os conceitos, bem como dados números, acerca dos temas, apresentados nos estudos dos autores consultados e estudados, assim como, as legislações, estaduais e federais, apresentados na fundamentação teórica, destacando as principais ideias e deliberações, visando à compreensão das questões fundamentais.

A adoção da abordagem qualitativa se opõe ao pressuposto de defesa de modelo único de pesquisa para todas as ciências, já que as ciências sociais têm sua especificidade, pressupondo, portanto, uma metodologia própria. Dentro desse contexto, ao utilizar os métodos qualitativos, a pesquisadora recusa o modelo positivista que se aplica ao estudo da vida social, tendo em vista por poder inferir e fazer julgamentos acerca da temática.

Ao utilizar na pesquisa o método qualitativo, a pesquisadora trabalhou com valores, crenças, representações, hábitos, atitudes e opiniões, possibilitando informações às indagações e questionamentos, subsidiando informações que promoverão subsídios para melhoria da questão que envolve a abordagem da inclusão, a partir das competências, para as funções exercidas pelos professores das escolas públicas.

Dessa forma, a percepção é de que o objetivo da pesquisa qualitativa consiste no aprofundamento da compreensão dos fenômenos que investiga, com critério e rigor, na perspectiva um bom resultado, tendo em vista conforme estudos de Flick(2013) se caracterizar como sendo uma tentativa de permitir a compreensão detalhada dos significados e características situacionais apresentadas, não somente dos estudos, mas, também, dos documentos analisados.

Cabe aqui mencionar que em relação aos estudos, em um primeiro momento estes foram as análises dos posicionamentos dos autores acerca da temática, aos quais foram balizados pela evidência das normatizações, programas, leis e decretos que validam, através de documentos oficiais, que dispõe sobre a normatização que rege o serviço público, bem como o processo formativo daqueles que atuam na área da educação. 
E ainda, dentro desse contexto para este trabalho, os procedimentos metodológicos compreenderam a pesquisa bibliográfica. A pesquisa bibliográfica abrange toda teoria já tornada pública em relação ao tema de estudo, desde publicações avulsas, jornais, revistas, livros, pesquisas, monografias, teses, etc., envolvendo teorias que já receberam um tratamento científico, possibilitando, a partir da análise, refletir sobre as contribuições desenvolvidas em diversas temáticas.

\section{CONSIDERAÇÕES FINAIS}

Com o desenvolvimento desta pesquisa ficou evidente que a Educação para Jovens e Adultos passou por grande transformação, surgindo como uma oportunidade de aprendizagem, inicialmente para as crianças ministradas pelos Jesuítas, e posteriormente para jovens e adultos e também como oportunidade de ensino para os professores das escolas públicas.

Ficou esclarecido que muitas foram as lutas que a história da educação brasileira passou em prol da permanência da Educação para Jovens e Adultos no Brasil, com o desenvolvimento de diversas campanhas e programas que visavam tornar a sociedade mais igualitária e ter uma educação inclusiva e não exclusiva, e que ainda são constantes.

Notou-se também que os problemas enfrentados, no que tange a cidadania, igualdade e formação, não afetam apenas os alunos, mas também os professores das escolas públicas, que buscam incansavelmente por condições mais iguais para melhor cooperar no processo de aprendizagem dos alunos jovens e adultos.

Assim, conclui-se que a Educação para Jovens e Adultos necessita de políticas públicas que resgatem o direito à cidadania, a dignidade, ao respeito, a valorização dos educandos e dos educadores, como forma de garantir sua inserção na sociedade, acesso integral à aprendizagem e ensino, ao conhecimento e a permanência na escola com direito a materiais didáticos adequados, fardamento, mobílias em perfeito estado e merenda escolar de qualidade. 


\section{REFERÊNCIAS}

ARROYO, Miguel. Educação em temos e exclusão. In: FRIGOTO, G.; GENTILLI, P. (Org.). A cidadania negada: políticas de exclusão na educação e no trabalho. São Paulo: Cortez, Buenos Aires, Clacso, 2001.

CARDOSO, G. da S. Mapeamento das competências funcionais: estudo de caso em uma empresa de celulose e papel. 2006. 171 f. Dissertação (Mestrado em Engenharia de Produção) - Universidade Tecnológica Federal do Paraná. Ponta Grossa, 2006.

CEITIL, M. (Org.). Gestão e desenvolvimento de competências. Lisboa: Edições Sílabo, 2006.

CRUZ, C. Competências e habilidades: da proposta à prática. São Paulo: Edições Loyola, 2001.

FURTADO, R.; NETO, AM. Uma contribuição para a construção de um modelo de análise da gestão participativa de empresas. Anais do Encontro Nacional de Pós-graduação e Pesquisa em Administração, Natal, RN, Brasil, 2007.

KUENZER, Acácia Zeneida. As políticas de formação: a construção da identidade do professor sobrante. Educação e Sociedade. Campinas, SP: CEDES, n. 68, dez., 2000.

MCCLELLAND, DC. Testing for CompetenceratherthanIntelligence., 1973, In:

FLEURY, MTL. Construindo o conceito de competência, Rev. adm. contemp., v. 5, n. esp., 2001.

PEREIRA, Júlio Emílio Diniz. Formação de professores: pesquisas, representações e poder. Belo Horizonte: Autêntica, 2005

PERRENOUD, Philippe. Construir as competências desde a escola. Porto Alegre: ARTMED, 1999.

PERRENOUD, P. Escola e cidadania. O papel da escola na formação para a democracia. Porto Alegre: Artmed Editora, 2005.

PERRENOUD, P. Porquê construir competências a partir da escola? Porto: Edições Asa, 2001.

REY, B.; CARETTE, V.; DEFRANCE, A.; KAHN, S. As competências na escola. Aprendizagem e avaliação. Vila Nova de Gaia, Portugal: Gailivro, 2005.

ROLDÃO, M. Gestão do currículo e avaliação de competências: as questões dos professores. Lisboa: Editorial Presença, 2003.

SCHÖN, D. Formar professores como profissionais reflexivos. In: Nóvoa, A. (Coord.) Os professores e a sua formação. Lisboa: Dom Quixote, 2000. 
ZARIFIAN, P. Objectifcompétence. Paris: Liaisons, 2001. 